This item was submitted to Loughborough's Institutional Repository (https://dspace.lboro.ac.uk/) by the author and is made available under the following Creative Commons Licence conditions.

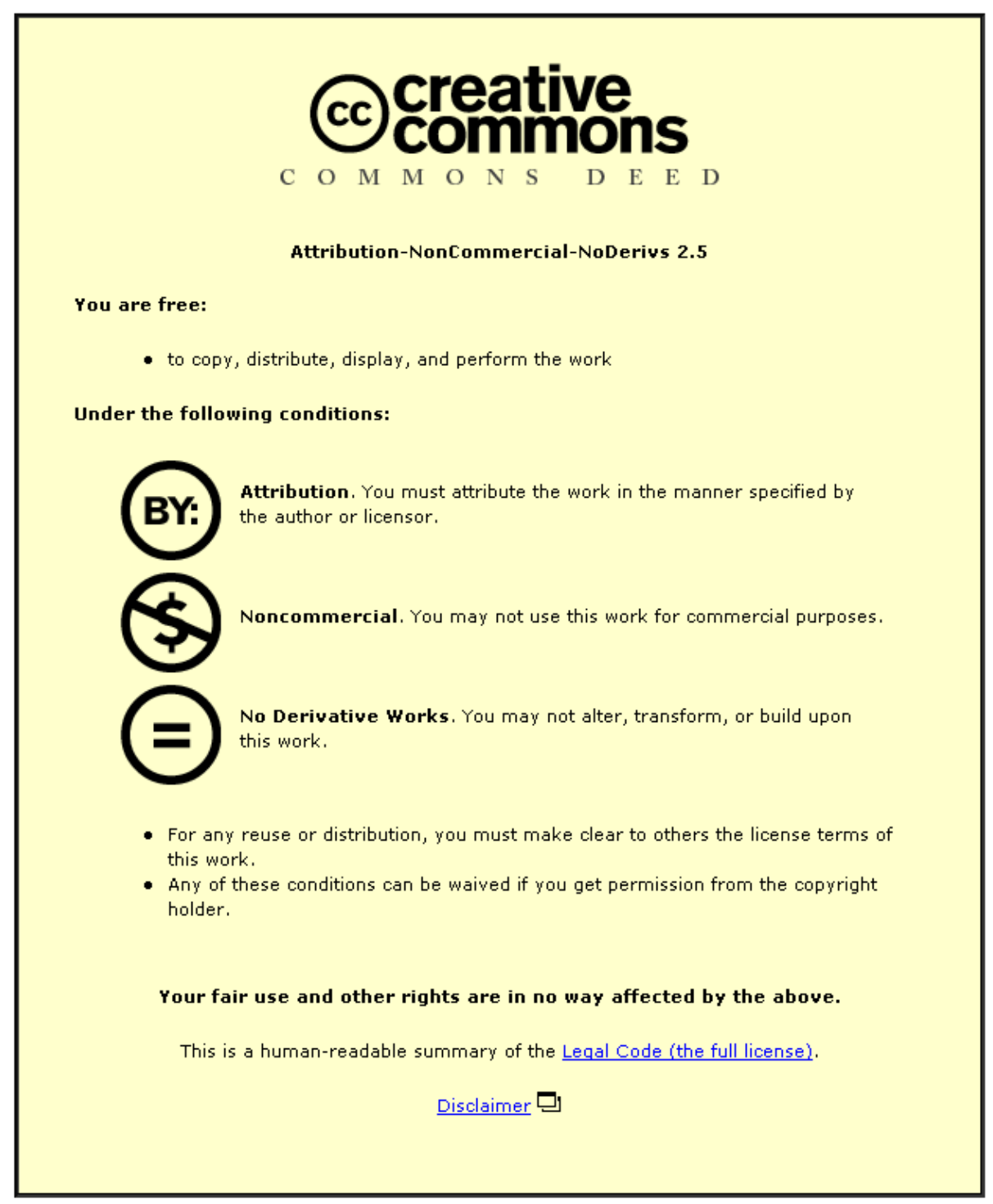

For the full text of this licence, please go to: http://creativecommons.org/licenses/by-nc-nd/2.5/ 


\title{
MODULAR ASSEMBLY WITH POSTPONEMENT TO IMPROVE HEALTH, SAFETY AND PRODUCTIVITY IN CONSTRUCTION
}

\author{
Peter F.Court ${ }^{1}$, Christine L. Pasquire ${ }^{2}$, Alistair G.F. Gibb ${ }^{3}$, David Bower ${ }^{4}$ \\ Court, P.F., Pasquire, C.L., Gibb, A.G.F. \& Bower, D., 2009, Modular Assembly with Postponement to Improve \\ Health, Safety and Productivity in Construction, ASCE Structural Design and Construction; American Society of \\ Civil Engineers, Vol 14., No 2., May 2009, pp.81-89, ISSN 1084-0680 - \\ http://cedb.asce.org/cgi/WWWdisplay.cgi?170819
}

\begin{abstract}
This paper presents the outcome of an engineering study as part of the design and development of a lean and agile construction system and in particular its supply chain component. This combines modular assembly with a postponement function to be tested on a case study project (not reported here), the objective of which is to improve health, safety and productivity for the company sponsoring the research.

The contribution to research is the combination of countermeasures described in this paper that have been developed and incorporated into a wider construction system, in the same way that manufacturing has used this strategy with great success. Also, a further output is the development and use of an innovative method for assembling, transporting and installing mechanical and electrical modules, whereby modularization can be achieved with or without offsite manufacturing capability. The research forecasts a reduction of onsite labor of $35 \%$ compared to using traditional methods of construction, with less onsite operatives at risk of injury carrying out simpler assembly tasks within ergonomic mobile work cells. Further research is proposed to measure the benefits of the construction system following its implementation on a case study project.
\end{abstract}

CE Database subject headings: Construction industry; Lean construction; Labor; Safety; Productivity; Prefabrication.

\footnotetext{
1 Research Engineer, Dept of Civil and Building Engineering, Loughborough University, UK, p.f.court@lboro.ac.uk

${ }^{2}$ Dept of Civil and Building Engineering, Loughborough University, UK. c.l.pasquire@lboro.ac.uk

${ }^{3}$ Dept of Civil and Building Engineering, Loughborough University, UK, a.g.gibb@lboro.ac.uk

${ }^{4}$ Principal Fellow, Warwick Manufacturing Group, University of Warwick, UK, bowerdjer@aol.com
} 


\section{INTRODUCTION}

This is a practical paper drawn from a collaborative research project (the research project) being undertaken at the Centre for Innovative Collaborative Engineering at Loughborough University, UK. The programme is funded by the Engineering and Physical Sciences Research Council (EPSRC) and is sponsored by a major UK mechanical and electrical (M\&E) contractor. The research project has specific objectives which will be capable of making a significant contribution to the performance of the sponsor company (the company).

The company is developing a construction system in order to improve the performance of its projects, and earlier research in this field (Court et al. 2005) has shown that lean interventions when applied to a case study project had positive results. The next phase of the research (Court et al. $2006,2007)$ using leading edge research and learning, designed a lean and agile construction system which is to be implemented on a major private finance initiative (PFI) hospital development, and in particular the mechanical and electrical elements within it (the case study project). This paper reports the next phase of the research project, which is the design of the supply chain component of the construction system, combining modular assembly with a postponement function. The paper will start by setting out the research project objectives, followed by background review of the UK construction industries health, safety and productivity performance. The underpinning theory and further related research findings are then presented which together form the basis of the design of the construction system. Following this the construction system itself is described, along with the case study project. The process to achieve the design of the modular assembly and postponement function is then set out, prior to the component itself being described. Finally, the expected benefits of the system are described (with certain results), conclusions are then drawn from this phase of the research and the next phase of research is proposed.

\section{Project Objectives}

The objective of this project for the company is to improve site operations, making them safer for the worker and to improve productivity as a countermeasure to the prevailing conditions in UK construction and the company itself. Safety is at the core of the company and according to the business leaders "...it is an absolute right for people to return home safely at the end of a productive day's work," and "failure to do so renders the company valueless." The key words here being safely and productive, these are therefore the key objectives of this research project, which is to design and implement a way of working on site, the countermeasures, that will satisfy these objectives. 


\section{INDUSTRY BACKGROUND}

According to the Health and Safety Executive (HSE) 2007, 2.2 million people work in Britain's construction industry making it the countries biggest industry. It is also one of the most dangerous. In the last 25 years over 2,800 people have died from injuries they received as a result of construction work. Many more have been injured or made ill. The HSE (2007a) have identified that construction also has the highest rate of musculoskeletal disorders (MSD's). These are mostly back injuries from manual handling. There were 56,000 work related MSD cases in construction in 2004/5. Handling injuries (to employees in 2004/5) accounted for $38 \%$ of over 3 day injuries and $15 \%$ of major injuries. In their research into MSD's, the HSE (2007b) have identified areas that can create a risk, which include; repetitive and heavy lifting; bending and twisting; repeating an action too frequently; uncomfortable working position; exerting too much force; working too long without breaks; adverse working environment (e.g. hot, cold); psychosocial factors (e.g. high job demands, time pressures and lack of control); not receiving and acting upon reports of symptoms quickly enough.

UK M\&E construction site productivity is poor. An investigative study by The Building Services Research and Information Association (BSRIA) set a foundation for understanding the problems and issues that the UK M\&E industry faces within the construction sector (Hawkins 1997). BSRIA compared UK, American, German and Swedish construction projects to highlight productivity problems relating to $M \& E$ building services to assist the UK M\&E industry in promoting improvements in productivity and to suggest remedies to solve these problems and improve performance. Significantly, the UK projects monitored had an average overall productivity of only $37 \%$ when compared to observed best practice and an average task productivity of only $56 \%$ by comparison. It found poorly conceived site parts storage and handling strategies which caused delays, with the very poorly performing projects being characterized by very poor levels of housekeeping. Workers were engaged in too much site cutting, drilling and assembly work and elevation of parts into final position. BSRIA report that labor costs typically constitute $30 \%$ of overall project M\&E costs, so maximizing the output on site is essential in order to increase a contractor's performance and the value for money investment of the customer.

The report, Innovative M\&E Installation (Wilson 2000), follows on from Hawkins (1997) and recommended that alternative systems, components, materials and innovative methods should be thoroughly evaluated to identify opportunities for productivity gains on M\&E projects. It concludes that the UK construction industry must replace outdated components and processes if it is to remain competitive in a global marketplace. This research found that the UK construction industry can realize a significant gain in installation performance through the adoption of innovative components 
and systems. Subsequent research conducted by BSRIA (Hawkins 2002) concluded that UK construction project teams that implemented improvement strategies and actions in accordance with the BSRIA best practice recommendations have realized significant improvements in site productivity. The research found that teams that designed for high site productivity used innovative components and exploited offsite manufacture realized a step-change improvement in construction site productivity rates. It also found that whilst the use of innovative products and offsite manufacturing techniques can deliver a huge improvement in project performance, their true value was still not being fully exploited. Court et al. (2005) describes how the increased cost of labor on recently completed major projects had a severe negative impact on the financial outcome of those projects and because of the scale of the cost overruns, the company itself.

\section{UNDERPINNING THEORY}

Manufacturing is seen as a rich source of research data for the adoption of lean and agile concepts into construction, therefore this was a primary source of theory for this research project. The research and learning has been used to develop a construction system that incorporates manufacturing concepts such as; modular assembly, postponement, reflective manufacture (including pulse driven scheduling - period flow control), and $A B C$ parts classification. This was reviewed and described by Court et al. (2006).

Modularity is a design strategy that is used by companies producing such different products as aircraft, household appliances, trucks and cars, computers and software. The concept is to divide a complex system into decoupled and manageable modules that are easily put together into a working whole (Fredriksson 2006). A definition is given by Fredriksson as the ability to pre-combine a large number of components into modules and for these modules to be assembled off-line and then bought onto the main assembly line and incorporated through a small and simple series of tasks. Postponement is an approach that helps deliver more responsive supply chains. Form postponement involves the delay of final manufacturing until a customer order is received and is commonly regarded as an approach to mass customization (Skipworth and Harrison 2004). Mass customization, is providing numerous customer chosen variations on every order with little lead time and cost penalty. The research proposes the application of form postponement as a solution to deal with the high demand uncertainty resulting from the provision of many variants, whilst ensuring low operational costs are maintained and short reliable lead times. If distribution of the product is delayed to the last minute and only configured and distributed when the customer order is received then you have logistics postponement (Yang and Burns 2003). Examples of how product architecture enables postponement are given in Ulrich and Eppinger (2004). They link the product 
architectural choices to platform planning, this being the collection of assets including component designs, shared by products. In Court et al. (2006) the customer requiring flexibility in the construction system is the construction site itself and in particular the semi-autonomous trade teams requiring exactly what they need when they need it. In Liker (2004) each person or step in a production line or business process was to be treated as a customer and to be supplied with exactly what was needed at the exact time needed. According to Liker, this was the origin of Deming's principle; the next process is the customer. Reflective manufacture evolves from Volvo's development of production systems which looked into quality of work as well as efficiency of production. Quality of work contains a number of aspects (Granath 1998). Granath suggests that a system that offers professional meaningful work is better than those that only offer unskilled or semi-skilled work. The aspects that signify professional work are; control over methods, time and quality plus the responsibility to plan ahead and the knowledge needed to reflect on work done. Quality of work also means good ergonomics, appropriate working tools and a good working environment. The system operates using a pulse system or period batch control. Period batch control (also know as period flow control) is a 'just-in-time', flow control, single cycle production control method, based on a series of short standard periods generally of one week or less (Burbidge 1996). Alternatively, the system operates using $A B C$ parts classification. In most manufacturing systems, a small fraction of the purchased parts represent a large fraction of purchasing expenditures so management should therefore focus most attention on these parts. $A B C$ classification is used to accomplish this (Hopp and Spearman 2001). Parts have been classified by Hopp and Spearman into A Parts - the first 5 to 10 percent of the parts accounting for 75 to 80 percent of expenditure; B Parts - the next 10 to 15 percent of the parts accounting for 10 to 15 percent of expenditure; and C Parts - the bottom 80 percent or so of the parts accounting for only 10 percent or so of expenditure. It makes sense therefore to use appropriate methods to tightly coordinate the arrival of $A$ parts. The cost of holding small excess quantities of $C$ parts is not large; therefore such methods would not be required for these. B parts are in between, so they deserve more attention than $\mathrm{C}$ parts, but less than $\mathrm{A}$ parts. The main point being that inventories of different classes of parts should be treated differently.

\section{FURTHER RESEARCH FINDINGS}

Related research findings to support this phase of the research are critical space analysis (Winch and North 2006), symbiotic crew relationships (Thomas et al. 2004) and sequence planning for electrical construction (Horman et al. 2006). According to Winch and North it is known that congestion on site reduces output and generates hazards. Thomas et al. report that symbiotic crew relationships occur 
when the pace of a crew depends on the pace of a preceding crew. Sometimes these relationships it was found are loose and relatively independent. At other times the relationships are tight and closely dependant. The research found that it is more common to have tight relationships in mechanical, electrical, plumbing and finishing trades. It defines this tight and dependant relationship as symbiotic. It found that the performance of crews with symbiotic relationships is shown to be consistently worse than when symbiotic relationships are not present. A method to avoid symbiotic relationships is recommended by simplifying the operations using preassemblies. This reduces the amount of work on site by fabricating and assembling M\&E modules offsite and simply installing these with a small installation team. Horman et al. report on factors that bear significantly on the performance of electrical contractors in building construction projects. It found that when project work sequences are poorly planned or poorly executed, electrical constructors often must contend with compressed schedules, trade stacking and out of sequence work.

Considering health and safety factors, occupational health has been ignored in favor of the more immediate, high impact occupational safety (Gibb 2006). Gibb argues that occupational health incidents are to be considered as "slow accidents" - the period over which the incident occurs may be lengthy and may creep up on you unawares. This implies that the result will be the same as an occupational accident; in that a worker gets injured but it just takes longer. Gibb's keynote paper reports that in the UK 4,500 construction workers are absent from work every day because of injuries caused by accidents, but there are 11,000 construction workers off sick at any one time with a work-related illness.

Research conducted for its better backs campaign (HSE 2000) found that a change to prefabricated modules for mechanical and electrical works and the use of mechanical aids to lift them significantly reduced the risk of manual handling injury. This enabled employees to maintain an improved posture when connecting and testing the units. Other benefits were found in the study including a considerable saving in time, no storage space required, no full floor scaffold required and improved consistency and quality of work.

In a research project looking into barriers and opportunities for offsite manufacture in the UK (Goodier and Gibb 2005), it is reported that the UK construction industry has a historically low level of training when compared with other industries and it is estimated that between 70 and $80 \%$ of the workforce in construction in the UK has no formal qualifications. Also a large proportion of the workforce are laborers, many of them self-employed, their skill base is narrow and their training is limited. It found also that there is an estimated annual turnover of between 65,000 and 75,000 people per annum in the industry. Significantly, the research found that electricians, joiners and 
bricklayers were the three skills generally cited the most by all the sectors questioned as being in short supply and contributing to the increased demand for offsite products.

Taken together these collective research findings form the underpinning theory for this research project and present a compelling case to do something to improve business as usual practice, which must be of benefit to the company and to the construction industry as a whole. The construction system is specifically designed to address these issues with appropriate countermeasures.

\section{THE CONSTRUCTION SYSTEM}

The construction system is the proposed methodology to deliver the objectives of the sponsor company and is represented in figure 1. Its underpinning theory incorporates manufacturing concepts such as modular assembly, postponement, reflective manufacture and $A B C$ parts classification (Court et al. 2006). Its key components are its supply chain with a postponement function and its lean site operations. The supply chain component has been categorized using $A B C$ parts classification with modules (type A) being delivered directly to site on a call-off system. Components and consumables (type $\mathrm{B}$ and $\mathrm{C}$ ) being parts kitted or replenished for delivery to site via the postponement function also on a call-off system and to the exact requirements for the site operations. The kits are to be postponed until the moment they are needed. Figure 2 shows a digital prototype of a corridor module (type A parts) together with distribution systems emanating from it and those around it (type B parts). Site operations are conducted by trade teams (T1, T2 etc) using mobile work cells and ergonomic access equipment (Court et al. 2005). The system operates using a pulse-driven system which has been called the week-beat. The site operations component of the construction system is the subject of separate research studies prior to its implementation on the case study project.

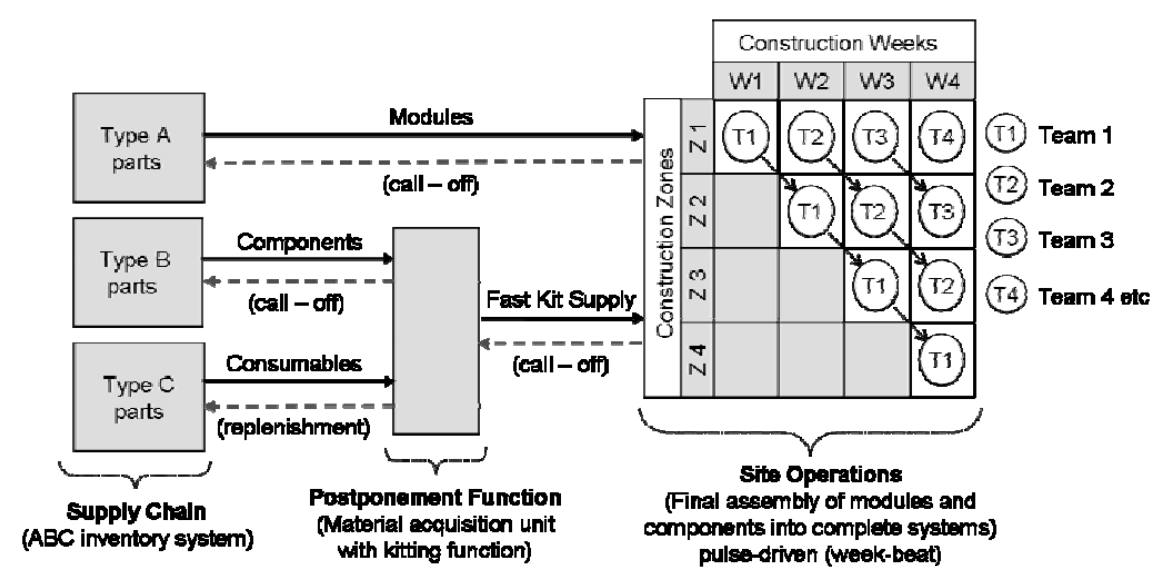

Fig. 1. The construction system (developed from Court et al. 2006, 2007, 2008). 


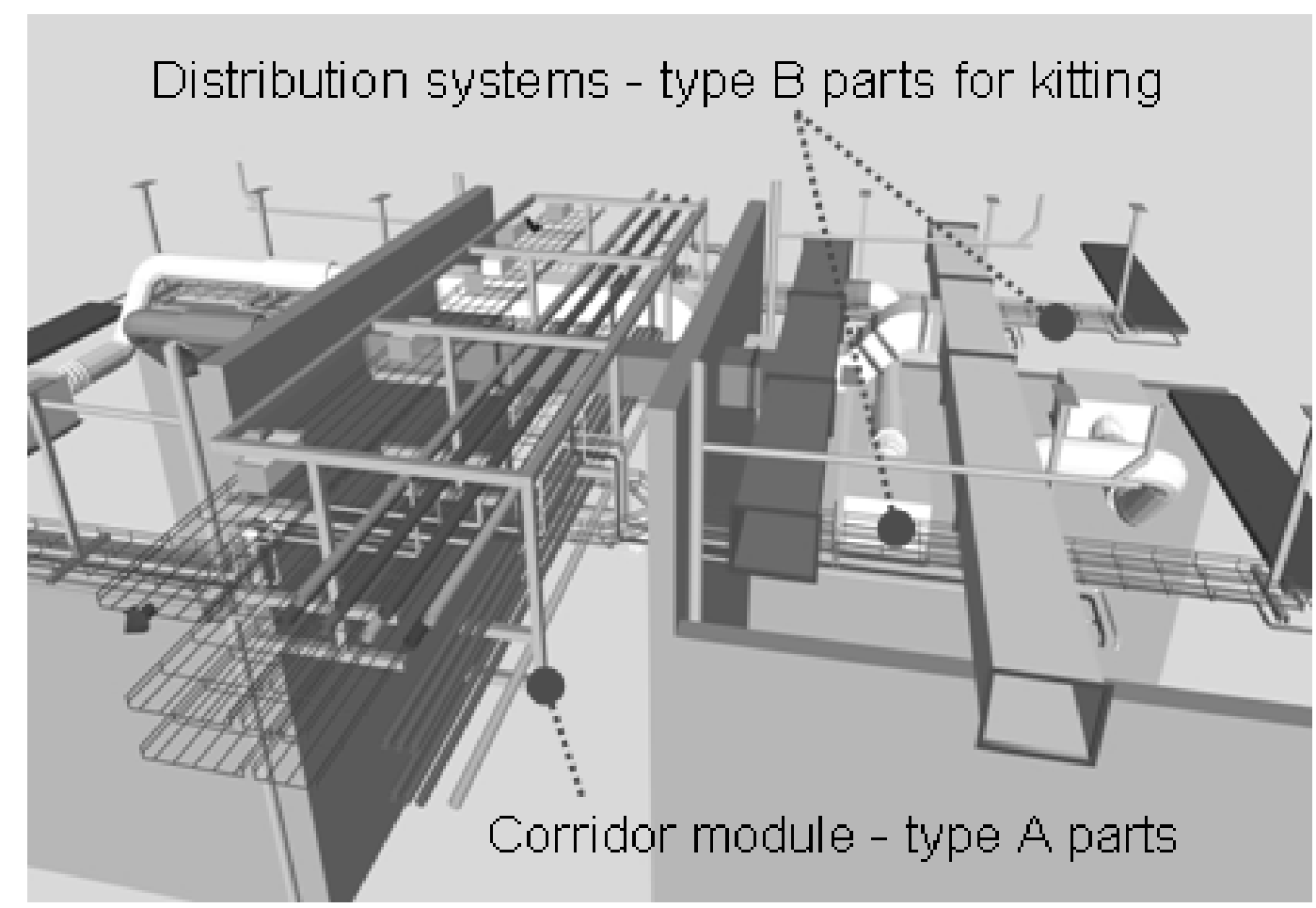

Fig. 2. Digital prototype of corridor module and distribution systems representing initial thinking.

\section{APPLICATION OF THE CONSTRUCTION SYSTEM}

\section{The CASe Study Project}

The case study project is part of the development of a major acute hospital being procured using the UK Government's Private Finance Initiative (PFI). The project is to be developed in phases across two existing operational hospitals. The phases are a new Maternity and Oncology Centre $\left(20,000 \mathrm{~m}^{2}\right.$ gross internal floor area); Sterile Services Department (2,000 $\mathrm{m}^{2}$ gross internal floor area), Hub and Wards Unit $\left(52,000 \mathrm{~m}^{2}\right.$ gross internal floor area); Diagnostic Treatment Centre $\left(20,000 \mathrm{~m}^{2}\right.$ gross internal floor area); Community Hospital - remote location (12,000 $\mathrm{m}^{2}$ gross internal floor area). The project commenced construction in December 2006 (M\&E commenced August 2007) and is due for completion in 2012.

The construction system is being applied on each phase of the case study project the first being the new Maternity and Oncology Centre. This is a $20,000 \mathrm{~m}^{2}$ building over four floors. It has electrical and water storage plant rooms in its basement with main ventilation plant rooms over the Oncology Centre at level two and on the roof at level five. Riser shafts are located around the building and distribute air, water, medical gas, electricity and the like throughout the building to the various departments. Corridor ceiling voids distribute the services from the riser shafts and then 
further into individual rooms and spaces, again in the ceiling voids. Finally, services distribute inside dry-lined walls to points of use such as electrical sockets, sinks, basins and bed-head units; everything you would expect to see in a new and modern healthcare facility.

Earlier work for this research project has described how the parts to be used that form the complete M\&E systems on the case study project were categorized using $A B C$ parts classification, with type $A$ being modules, type $B$ being loose components and type $C$ being consumables such as nuts, bolts, washers and the like. Described in this paper is the research involved in setting the supply chain strategy. This is to pre-assemble as much as possible offsite (type A parts) to be delivered just-in-time and incorporated into the final assembled systems along with component kits (type $B$ and $C$ parts) in a series of small and simple tasks. The labor strategy is also clear; to remove as much labor offsite as possible with those that remain provided with good ergonomics, appropriate working tools and a good working environment, thereby facilitating a quality of work.

\section{THE Process: Set BASEd ThINKING}

The M\&E elements for $A B C$ classification were agreed upon according to principles and ground rules pre-agreed by cross-functional teams. Liker (2004) called this set based concurrent engineering. This term was used to describe how Toyota developed vehicle designs using a cross-functional team of experts and the project leaders relied on that team. This was the starting point for actually deciding upon what chunks of the M\&E systems were to be modularized (type A parts), and what would be parts kitted or replenished (type B and C parts), as well as the selection of the actual components themselves. This activity was conducted in a workshop environment, with project team members assigned to the team because of their individual expertise. The team members were represented with the following disciplines: Project leader (one of the authors); offsite manufacturing engineer; construction manager; commissioning manager; maintenance engineer; mechanical and electrical engineer; mechanical design and electrical design engineer; architectural technician; structural engineer; procurement engineer and component suppliers. The initial activity was to agree upon the guiding principles, design parameters and ground rules so that decisions were made in the light of these and the team would not move forward unless each had been satisfied. Three overarching principles were set and these are:

PRINCIPLE 1 - INCIDENT AND INJURY FREE: People returning home safely every day after a productive days work; minimize on-site labor; health, safety and quality shall be the over-riding objectives of the design.

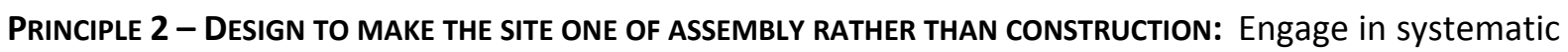
analysis of the elements and their interconnection; design for modular assembly; design for 
standardization; design solutions for re-use; engage the internal and external supply chain to deploy expertise early in the design process - design around a product.

Principle 3 - Use technology enablers: 3D/4D modeling (digital prototyping) is to be deployed throughout the project; fully integrated and co-ordinated, 3D common data structure; 3D intelligent objects provided by the internal \& external supply chain (not the subject of this paper).

The outputs of these workshops are described later in this paper. Together with the workshops for parts analysis, construction sequencing was also agreed with a cross-functional team. The team consisted of nominated members from the parts classification team, as well as M\&E, building, planning and specialist sub-contract trade personnel.

\section{InSTALLATION SEQUenCing For CONSTRUCtion}

A detailed analysis was undertaken of the installation sequencing, with particular emphasis on ensuring that no two or more trades would work in the same place at the same time, unless expressly designed to do so. The building is divided into construction zones; each being approximately $1,000 \mathrm{~m}^{2}$ (zones $1-17$, plant rooms 1-3). This area of construction zone being rightsized for each trade team to complete the planned work in a maximum five days. Here, team T1 has one week to complete its work before moving to the next zone. The next team, $\mathrm{T} 2$, follows on at the week-beat interval, and the next, T3, team follows similarly. Within each construction zone mechanical and electrical work has various sub-process activities, as do the building fabric works (dry-lining, ceilings, painting, flooring etc.). These tight and dependant relationship are what Thomas et al (2004) called symbiotic and these relationships exist within this project. Table 1 shows the agreed sequences between each M\&E process (MEP 1, 2, 3 etc.) and associated building fabric processes (BFP 1, 2, 3 etc.). Figure 3 represents a template construction zone process, mapped onto an assembly process as figure 1 in Fredriksen (2006). This shows the M\&E processes (MEP 1-5), and the building fabric processes (BFP 1-6). The process starts with a designated construction zone is made available for work and finishes when all operations are complete.

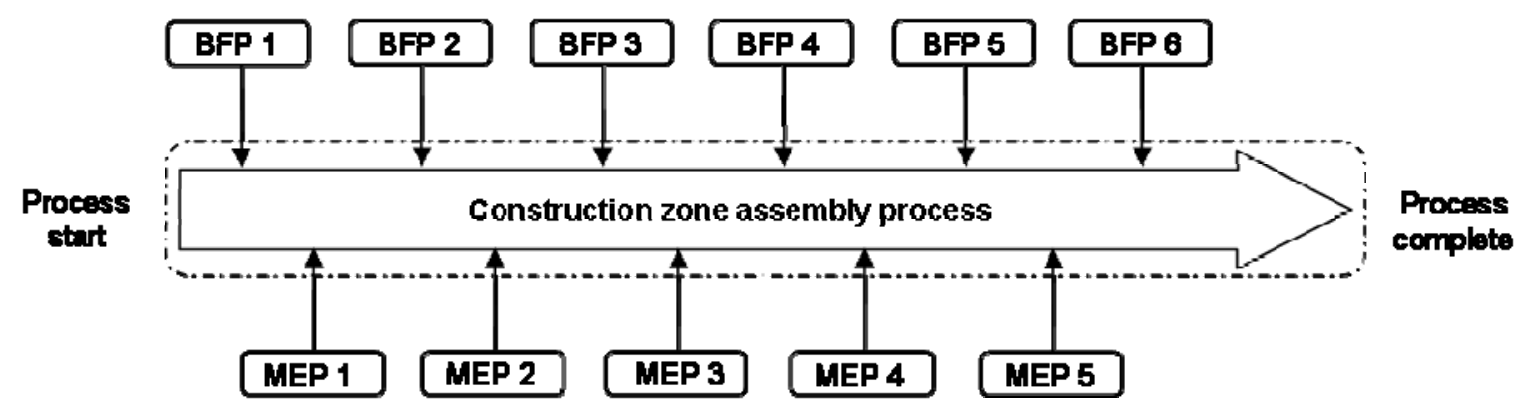

Fig. 3. Construction zone assembly process (developed from Court et al. 2007). 
Table. 1. Construction zone process and associated activity schedule (developed from Court et al. 2007).

\begin{tabular}{ll}
\hline \multicolumn{1}{c}{ Process } & \multicolumn{1}{c}{ Installation Activity } \\
\hline BFP 1 & Set datum's; mark out and fit dry lining header track. \\
MEP 1 & Drainage; ductwork; riser/corridor modules; distribution systems; insulation. \\
BFP 2 & Thin-bed screed; dry-lining studwork; first side dry-lining. \\
MEP 2 & Pipework and electrical conduit drops within dry-lining walls. \\
BFP 3 & Second side dry-lining; tape and joint; mist coat painting. \\
MEP 3 & Power and control cabling; medical gas pipe work; wall mounted equipment. \\
BFP 4 & Ceiling bulkheads; ceiling grid; service tiles for M\&E devices; door frames. \\
MEP 4 & Ceiling mounted equipment. \\
BFP 5 & Vinyl floor; final painting; door sets and ironmongery; cupboards; fixed furniture. \\
MEP 5 & Connections to equipment; floor mounted toilets; door mounted accessories. \\
BFP 6 & Ceiling tiles (excluding commissioning access tiles); carpets; final clean. \\
\hline
\end{tabular}

As can be seen in table 1, each M\&E and building fabric sequence has various sub-processes within it and MEP 1 has been shown in figure 4. MEP 1 consists of at least seven sub-processes each of these conducted by separate teams. This figure now shows the outputs of the $A B C$ classification team, where riser and corridor modules have been incorporated with the remaining MEP subprocesses being component supplied to be parts-kitted and postponed as described in this paper. MEP 2-5 follow a similar format, with sub-process components and modules being assembled together to form the final M\&E systems. These and subsequent assembly processes repeat in each construction zone with the aim of each sub-process being completed in the week-beat cycle. These processes rely on modules and parts being available in the right sequence and at the right time for the system to operate as planned. The approach to this is now described. 


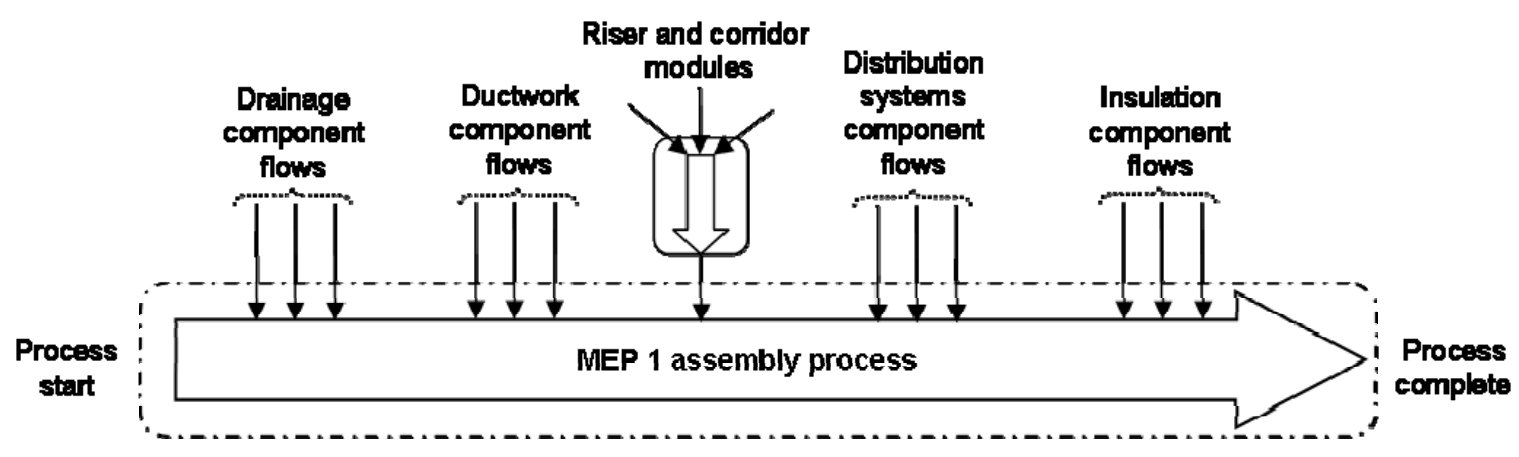

Fig. 4. Mechanical and electrical process 1 (developed from Court et al.2007, 2008).

\section{APPROACH TO MODULAR ASSEMBLY AND POSTPONEMENT FOR CONSTRUCTION ZONES}

In order to design the component flows into the case study project, the cross-functional teams developed a logistics strategy to guide the teams thinking through the process, which is set as follows: There will not be a big central store of parts waiting to be used or workers having to walk to and from stores to collect parts. However, there will be parts on site today, being what is needed tomorrow with inventory check-lists used to guarantee complete kits are provided; Modules (type A parts) delivered direct to the point of use and incorporated using mechanical lifting gear by manual handling operatives; a logistics team delivering kits of type B parts for the next days work on carriers which are moved straight the point of use and replenishing type $C$ parts into mobile work centers according to use. This logistics strategy set the thinking for how materials are to flow into the site. Because $A B C$ parts are procured according to their type their supply chain source needed to be understood. To assist this, parts were further categorized into made-to stock and made-to-order type. A lean ideal for the championship, prefabrication and assembly, is to simplify site installation to final assembly and commissioning (Ballard and Matthews 2004). In this ideal products used in the building process have been divided into made-to-stock (MTS) and made-to-order (MTO). An example of this further categorization is presented in table 2 for MEP1 and plant room assembly processes. Other MEP processes (MEP 2-5) follow a similar format. 
Table. 2. Example of $A B C$ parts by MTS and MTO for MEP 1 and plant rooms.

\begin{tabular}{|c|c|c|c|c|}
\hline $\begin{array}{c}\text { Proces } \\
\mathrm{s}\end{array}$ & $\begin{array}{c}\text { Type A Parts } \\
\text { MTO }\end{array}$ & $\begin{array}{c}\text { Type B Parts } \\
\text { MTO }\end{array}$ & $\begin{array}{c}\text { Type B Parts } \\
\text { MTS }\end{array}$ & $\begin{array}{c}\text { Type C Parts } \\
\text { MTS }\end{array}$ \\
\hline MEP 1 & $\begin{array}{l}\text { Riser modules; } \\
\text { corridor modules. }\end{array}$ & $\begin{array}{l}\text { Ductwork and } \\
\text { fittings; } \\
\text { composite } \\
\text { brackets. }\end{array}$ & $\begin{array}{l}\text { Pipework and fittings; } \\
\text { electrical tray and } \\
\text { fittings; fire stopping } \\
\text { sleeves; insulation. }\end{array}$ & $\begin{array}{l}\text { Nuts; bolts; } \\
\text { washers; } \\
\text { screws; clips } \\
\text { etc. }\end{array}$ \\
\hline $\begin{array}{l}\text { Plant } \\
\text { rooms }\end{array}$ & $\begin{array}{l}\text { Plant items; plant } \\
\text { modules; distribution } \\
\text { modules; electrical } \\
\text { panels etc. }\end{array}$ & $\begin{array}{l}\text { Ductwork and } \\
\text { fittings; } \\
\text { composite } \\
\text { brackets. }\end{array}$ & $\begin{array}{l}\text { Pipework and fittings, } \\
\text { electrical tray and } \\
\text { fittings; cables; } \\
\text { insulation. }\end{array}$ & $\begin{array}{l}\text { Nuts; bolts; } \\
\text { washers; } \\
\text { screws; clips } \\
\text { etc. }\end{array}$ \\
\hline
\end{tabular}

When designing this system of concern to the teams was the potential fragility of the system. A production system which culminates with just-in-time (JIT) is very efficient if everything runs perfectly, but is extremely fragile if there is any kind of problem whatsoever (Forza 1996). Further, in order to be able to function in a lean system, all the resources being used in the production process have to be foreseeable and reliable. The construction system has the potential to be fragile in this way as it is not embedded in company operations and tried and tested. Therefore component flows into the project have to be foreseeable and reliable in order for the construction system to work as planned. Safety stock and safety lead times can be used as protection against these problems (Hopp and Spearman 2001). Safety stock should be used to protect against uncertainties in production and demand quantities, while safety lead time should be used to protect against uncertainties in production and demand timing. These countermeasures have therefore been built into the construction system. Resource capacity buffers are built into site operations which is the subject of separate research studies. Safety stock in the system has been provided both on site and in the supply chain for MTS type B and C parts. These parts are purchased from national framework suppliers and held in stock at a local branch. The kits provided to site are delivered today for use tomorrow giving a one day stock buffer on site. A construction zone takes one week to complete in the week-beat cycle and supplier's agreements are to keep two zones of parts in stock at the local branch. Replenishment is signaled when parts for a zone have been depleted, giving a week safety stock buffer in the system, but offsite. Site replenishment from the local branch signals replenishment from the central warehouse to the local branch, who replenishes it with a zone every week. The central warehouse operates a 12 week stock-turn giving an 11 week safety stock buffer 
further back in the system. This relies on global project quantities being advised by the project to the supply chain, which has been done. Safety lead time in the system is provided in the supply chain for MTO type A and B parts. MTO type A modules given their size and complexity are required to be delivered directly to the point of use and their lead time has been incorporated into the master schedule. A safety buffer of at least two weeks has been built-in dependant upon the module type to protect against any disruption to production and site demand. MTO type B components have a lower lead time than modules and again safety lead time for these has been built into the master schedule to protect against any unforeseen problems that may occur.

\section{Construction Zone And Plant Room Modules (TYPe A PARTS - MTO)}

An important point to note is that the company has its own manufacturing centre which has been producing modular M\&E assemblies since the mid 1990's, and has previously been the subject of research studies (Pasquire and Connolly 2002, Pasquire and Connolly 2003). The authors believe that the contribution to research is how modularization can be incorporated into a wider construction system in the same way that manufacturing has used this strategy. Also, by using an innovative method for assembling, transporting and installing corridor and riser modules (MEP 1 sub-processes), as described later in this paper, elements of modularization can be achieved with or without manufacturing capability.

In figure 2 the initial corridor module design shows a rigid welded unistrut steel frame which contains the M\&E components within it. However, once the module has been installed, most of the steel frame is redundant, therefore not adding value to the module other than during assembly and transportation from the place of manufacture (manufacturing centre). This adds additional cost to the module, which has been seen as a barrier to offsite manufacture (Goodier and Gibb 2005). To overcome this, an assembly, transportation and installation frame (ATIF) was conceived. Here modules are assembled in the manufacturing centre, transported to site, incorporated into the building using mechanical hoists with the ATIF returning to the manufacturing centre for re-use. Figure 5 shows digital prototypes of three stages of this sub-process. The modules when lifted on the ATIF are bolted to cast-in unistrut inserts running in tram-lines along corridor positions in the concrete soffit. This avoids the need for workers drilling for fixings into concrete, reducing the risk of injury from hand-arm vibration. The modules and ATIF's have been standardized during the design process, in that there are two corridor widths and two corridor ceiling void heights giving four size combinations. 

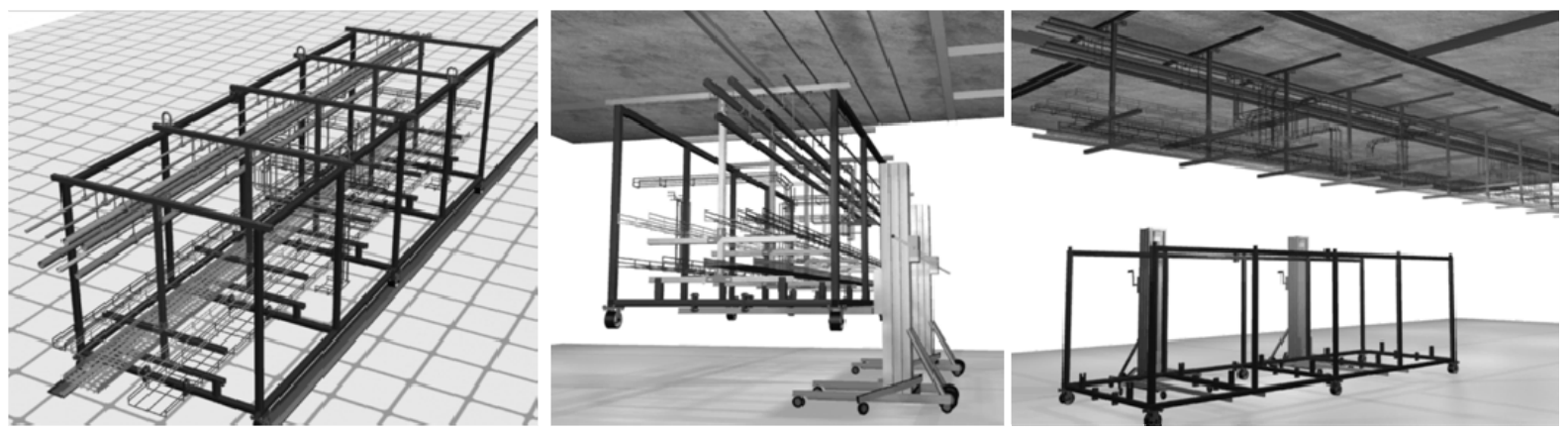

Fig. 5. ATIF ready in manufacturing centre; elevation onsite using mechanical lifting hoists; modules installed with ATIF to be returned to manufacturing centre for re-use (developed from Court et al. 2008).

The ATIF is designed to accommodate each of these four sizes by being reconfigurable via removable or adaptable components. It is calculated that 40 ATIF's are required in the system and with approximately 1,500 corridor modules required for the entire project, 1,460 welded frames as shown in figure 2 are saved. Also the ATIF's can be re-used on other projects or their steelwork recycled for other uses. The modules are assembled and pressure tested in sets of five on a production line at the manufacturing centre which proves connectivity and alignment. Four are delivered for a day's assembly on site with one remaining. The remaining module is then used with the next four which are assembled to prove connectivity and alignment; this and three from the new set are then delivered to site, and so on. Fundamentally each module is a standard platform (the ATIF and bracketry), with the components within it (pipes, cable containment etc.) being configured specifically to the requirements of the space it serves. Such a strategy provides mass customization. The components selected are push-fit, crimp or clamp type pipe systems, and cable trays (basket type) that connect together also with quick fit couplings. Branch pipes for onward distribution into rooms end with a valve for quick connection to distribution into the adjacent rooms. Pipes, once tested, are insulated at the manufacturing centre with the exception of joints and valves which are insulated on site, once system testing is complete. Riser modules are also assembled at the manufacturing centre and these are single storey risers containing pipe work, ductwork or electrical components, or any combination of the three. A steel riser floor is cast-in to the concrete slab as these progress, with each pipe, duct or bus-bar opening pre-cut and capped off, which is removed just prior to the riser being positioned. Where risers are not heavily populated with M\&E services, these are assembled onsite using pre-assemblies and kits of associated parts. Plant room components such as pump sets, pressurization units, valve stations etc. are grouped together and assembled offsite into plant room modules by the company. These are also wired and insulated at 
the manufacturing centre to further reduce the amount of work on site. Interconnections between plant modules and risers are site assembled also using pre-assemblies and kits of associated parts.

\section{CONSTRUCTION ZONE COMPONENT Flows (TYPE B AND C PARTS - MTO AND MTS)}

The approach to manage the flow of components to the point of use has been described earlier in this paper, which is to kit the specific parts for the MEP operation and postpone its delivery until it is needed. The kitting itself is carried out using MTO and MTS suppliers as re-packing centers and decoupling points. Bertelsen et al. (2006) describe previous experiments using this approach. Each of the components is selected to be quick-fit, commercially available and tried and tested technology. Small pipe work for water and drainage is either push-fit, crimp-fit or clamp type. Larger pipes are welded and flanged, but made offsite. Electrical trays are basket, trunking or ladder type which fit together quickly with snap-on couplings. Power cables for small power and lighting is a modular plug-and-play connectable system configured on site from standard MTO components. Larger armored cables for main power supplies are standard type MTS and delivered on large cable drums. Low voltage cables (data, BMS, nurse call etc.) are also standard items on small drums or boxed as appropriate. Where components can be assembled together operatives and tools are provided at the local supplier's branch to pre-form conduits and assemble pipe clips onto brackets and the like. Each of these components are delivered to site in purpose made roll cages or similar, with kits offloaded from the point of delivery and delivered to the point of use by a logistics team trained in manual handling methods, thereby avoiding the need for installation team members to do this.

\section{LABOR AND ASSOCIATED COST FORECAST}

Combining offsite modular assembly and postponement with the lean site operations component of the construction system and projecting the labor required to perform the planned operations forecasts a $35 \%$ reduction of onsite labor. This forecast is derived from a comparison of calculated estimates of labor times between conducting the work using traditional methods and by using the construction system as described in this paper. For all MEP processes, including plant rooms, the traditional method is estimated at 202,800 hours, with the construction method estimated at 131,040 hours. This equates to a difference of 71,760 hours between the two methods; a $35 \%$ reduction. Also, because of the simplification of the assembly process, a lower ratio of skilled to semi-skilled operatives is required, which reduces the average hourly cost of labor. This will further reduce the outturn labor cost of the project. A reduction in total cycle-time is also achieved using the system however, at this stage of research this is kept as a time buffer between M\&E construction and commissioning. The reduction in forecasted labor does not represent an overall 
forecasted labor saving, as work has shifted offsite for modular assembly; it represents a reduction in labor onsite.

The sub-process within MEP1, corridor modules (ATIF's) has been evaluated (once the work was complete) and reported in Court et al. (2008). Here 1,568 actual onsite hours were required elevating and connecting together a total of 196 modules, compared to 22,320 hours estimated using traditional methods with various trade teams completing the required work all working at height; a 93\% reduction. An $8.62 \%$ cost benefit is also reported. This cost analysis compares an estimate of traditional method against actual offsite method including: basic materials; material waste; labor including supervision and testing; productivity losses; transport costs; site equipment; rectification and rework costs and design costs. Productivity losses means a cost factor estimate of the productivity losses possible between the different methods, including weather, stoppages, damage, theft and interferences etc. The estimated cost of this has been assessed as $25 \%$ of traditional installation labor only to demonstrate this variable. As the paper reports, the value of this variable provides the cost benefit assessed between the different methods. In other words, if estimated productivity losses for the traditional method were zero percent, then there would be no cost benefit of the offsite method; but this is unlikely in the opinion of the authors and according to previous research (Hawkins 1997). This measured average overall productivity as $37 \%$ on the UK projects monitored. In essence, the increased offsite costs for manufacturing centre overhead, additional transport and assembly drawings are more than offset by the higher onsite costs related to productivity, supervision, site testing and rework. When this benefit has been combined with the results emerging from the implementation of the construction system through all MEP processes, a final analysis against overall forecasted benefits will be made and reported in future research papers.

\section{CONCLUSION}

This paper has presented the outcome of an engineering study (and certain results) as part of the design and development of a lean and agile construction system and in particular its supply chain component combining modular assembly with a postponement function for a designated building phase within a case study project. The construction system component described in this paper has been developed as a specific set of countermeasures to overcome what would otherwise occur had these interventions not been made. Modular assembly using mechanical lifting aids will significantly reduce the risk of manual handling injury to workers. It will need fewer operatives to carry out the simpler assembly tasks required and risk of injury is reduced by having fewer workers operating at height. It is also a method to avoid symbiotic relationships that would otherwise exist which will 
increase the performance of crews carrying out their operations. Congestion on site will be reduced which itself will eliminate the generation of hazards and increase the output of workers. Productivity will be improved because less work is required on site by workers cutting, drilling, assembly and elevating parts into position using traditional methods. Furthermore, a significant gain in installation performance will be achieved as the system has adopted innovative quick-fit components and systems. Postponing kits of parts offsite until the time they are needed will avoid the poor site storage and handling strategies that BSRIA report which have shown to be the cause of delays and lost productivity in UK M\&E construction. By managing the flows of components in this way will enable trades to perform their operations as planned avoiding potential trade stacking and out of sequence working that has been seen to occur. This research has forecast that a reduction of $35 \%$ of onsite labor can be achieved and a lower skill mix is required to perform the simpler assembly tasks as a result. A further benefit of this is that the company avoids the potential risk they face due to the shortage of trained workers available in UK construction, with the lower skill mix resulting in a reduced average labor cost on the project. Whilst certain elements of what has been described in this paper are common practice in the UK M\&E industry, the authors believe that the contribution to research is the combination of countermeasures described that have been incorporated into a wider construction system, in the same way that manufacturing has used this strategy. Also by developing an innovative method for assembling, transporting and installing corridor and riser modules, using an ATIF, modularization can be achieved with or without offsite manufacturing capability. In fact, this approach can be adopted by M\&E contractors on site, but offline. Space permitting, a small assembly workshop can be set up adjacent to a construction site to carry out this process, or supply chain partners can be developed and encouraged to use this method. Also, parts-kitting can be achieved by the supply chain according to the principles set out in this paper. If distances for transportation are too great, then again this function could be carried out on a construction site, but not at the point of use, as is traditionally seen. This should be done offline by a logistics team, and not by the workers themselves. This construction system component presents a set of countermeasures that are designed to overcome what traditionally occurs on UK construction sites as this research paper has described and to meet the stated research project objectives; which is to design a way of working on site for improved health, safety and productivity for the company.

\section{FURTHER RESEARCH}

The next phase of research will be to test the construction system and measure the results emerging from the implementation on a case study project. This will be for the M\&E work associated with the 
Maternity and Oncology Centre, a phase within the case study project. This implementation phase will test the system by measuring the expected benefits which is to avoid the risk of incidents or injury to workers, have less workers onsite carrying out simpler assembly tasks, and with improved productivity to maintain the labor cost centre budget thereby defending the company's margin on the project (Court et al. 2005).

\section{REFERENCES}

Ballard, G. and Matthews, O. (2004). "Championship - prefabrication and assembly." Proc., Twelfth Annual Conf. of the Int. Group for Lean Construction (IGLC-12), Elsinore, Denmark, 625-628.

Bertelsen, S., Koskela, L., Henrich, G., and Rooke, J. (2006). "Critical flow-towards a construction flow theory." Proc., Fourteenth Annual Conf. of the Int. Group for Lean Construction (IGLC-14), Santiago, Chile, 31-40.

Burbidge, J.L. (1996). Period batch control, Oxford University Press, New York, USA.

Court, P., Pasquire, C., Gibb, A.G.F., and Bower, D. (2005). "Lean as an antidote to labour cost escalation on complex mechanical and electrical projects." Proc., Thirteenth Annual Conf. of the Int. Group for Lean Construction (IGLC-13), Sydney, Australia, 3-11.

Court, P., Pasquire, C., Gibb, A.G.F., and Bower, D. (2006). "Design of a lean and agile construction system for a large and complex mechanical and electrical project." Proc., Fourteenth Annual Conf. of the Int. Group for Lean Construction (IGLC-14), Santiago, Chile, 151-164.

Court, P., Pasquire, C., Gibb, A.G.F., and Bower, D. (2007). “Transforming Traditional Construction into a Modern Process of Assembly using Construction Physics." Proc., Fifteenth Annual Conf. of the Int. Group for Lean Construction (IGLC-15), Lansing, USA, 345-356.

Court, P., Pasquire, C., Gibb, A.G.F., and Bower, D. (2008). "Modular Assembly in Healthcare Construction - A Mechanical and Electrical Case Study." Proc., Sixteenth Annual Conf. of the Int. Group for Lean Construction (IGLC-16), Manchester, United Kingdom, 521-531.

Fredriksson, P. (2006). "Mechanisms and rationales for the coordination of a modular assembly system - the case of Volvo cars." Int. J. of Ops. and Prod. Manage., Vol 26 No. 4, 350-370.

Forza, C. (1996). "Work organisation in lean production and traditional plants - what are the differences?" Int. J. of Ops. Manage., Vol. 16. No. 2, 1996, 42-62.

Gibb, A.G.F. (2006) (Keynote). “Occupational health: slow accidents need solutions fast," in Fang, Choudry \& Hinze (eds), Global Unity for Safety \& Health in Construction, Proc., of CIBW99 Int. Conf., June 2006, Beijing, Tsinghua University Press, 22-33. 
Goodier, C.I., Gibb, A.G.F. (2005). "Barriers and opportunities for offsite in the UK." Systematic Innovation in the Management of Projects and Processes. Abdul Samad Kazi (ed), cib Helsinki international joint symposium, 148-158.

Granath, J.A. (1998). "Torlanda to Uddevalla via Kalmar: a journey in production practice in Volvo." Seminário Internacional Reestruturaçã Productiva, Flexibilidade do Trabalho e Novas Competências Profissionais, COPPE/UFRJ, Rio de Janeiro, Brasil.

Hawkins, G. (1997). "Improving M\&E site productivity." BSRIA technical note TN 14/97, The Building Services Research and Information Association, Bracknell, UK.

Hawkins, G. (2002). Site Productivity - 2002. "A guide to the uptake of improvements." BSRIA technical note TN 13/2002, The Building Services Research and Information Association, Bracknell, UK.

Health and Safety Executive. (2000). "Backs for the future: safe manual handling in construction." HSE books, Norwich, UK.

Health and Safety Executive. (2007). "Health and safety in the construction industry." <http://www.hse.gov.uk/construction/index.htm> (Mar. 4, 2007).

Health and Safety Executive. (2007a). "Better backs in construction." <http://www.hse.gov.uk/construction/backs/index.htm> (Mar. 4, 2007).

Health and Safety Executive. (2007b). "Musculoskeletal disorders - HSE and MSD's." <http://www.hse.gov.uk/msd/hsemsd.htm> (Mar. 4, 2007).

Hopp, W. J., and Spearman, M. L. (2001). "The MRP crusade." Factory physics, $2^{\text {nd }}$ Ed., Irwin/McGraw-Hill, New York, USA, 109-150.

Horman, M. J., Orosz, M. P., and Riley, D. R. (2006). "Sequence planning for electrical construction." J. Constr. Eng. Manage., 132(4), 363-372.

Liker, J. K. (2004). The Toyota Way: 14 management principles from the world's greatest manufacturer, McGraw-Hill, New York, USA.

Pasquire, C.L., and Connolly, G.E. (2002). "Leaner construction through off-site manufacturing." Proc., Tenth Annual Conf. of the Int. Group for Lean Construction (IGLC-10), Gramado, Brazil, 263275.

Pasquire, C.L., and Connolly, G.E. (2003). "Design for manufacture and assembly." Proc., Eleventh Annual Conf. of the International Group for Lean Construction (IGLC-11), Blacksburg, Virginia, 184-194.

Skipworth, H., and Harrison, A. (2004). "Implications of form postponement to manufacturing: a case study." Int. J. Prod. res., 15 May 2004, vol. 42, no. 10, 2063-2081. 
Thomas, H. R., Horman, M. J., and de Souza, U. E. L. (2004). "Symbiotic crew relationships and labor flow." J. Constr. Eng. Manage., 130(6), 908-917.

Ulrich, K. T., Eppinger, S. D. (2004). "Product architecture." Product design and development, $3^{\text {rd }}$ Ed., McGraw Hill, New York, USA, 163-186.

Wilson, D. (2000). “Innovative M\&E installation." BSRIA ACT 9/2000, The Building Services Research and Information Association, Bracknell, UK.

Winch, G. M., and North, S. (2006). "Critical space analysis." J. Constr. Eng. Manage., 132(5), 473481.

Yang, B., and Burns, N. (2003). "Implications of postponement for the supply chain." Int. J. Prod. res., 2003, vol. 41, no. 9, 2075-2090. 